\title{
Analysis of the Stress Distribution Pattern of Anatomic and Non-Anatomic Tooth Forms on Maxillary and Mandibular Edentulous Ridges-A Photoelastic Study
}

\author{
T. K. Chandrathara1, M. Lovely2*, Eldo Koshy ${ }^{3}$, Jitendra Jethwani ${ }^{4}$ \\ ${ }^{1}$ Department of Prosthodontics, Sri Sankara Dental College, Trivandrum, India \\ ${ }^{2}$ Department of Prosthodontics, Ras Al-Khaimah College of Dental Sciences, Ras Al Khaimah, UAE \\ ${ }^{3}$ Dr. Koshy's Dental Clinic, Cochin, India \\ ${ }^{4}$ School of Dentistry, Virginia Commonwealth University, Richmond, VA, USA \\ Email: *lovely.muthiah@rakmhsu.ac.ae
}

How to cite this paper: Chandrathara, T.K., Lovely, M., Koshy, E. and Jethwani, J. (2020) Analysis of the Stress Distribution Pattern of Anatomic and Non-Anatomic Tooth Forms on Maxillary and Mandibular Edentulous Ridges-A Photoelastic Study. Journal of Biosciences and Medicines, 8 , 113-126.

https://doi.org/10.4236/jbm.2020.86011

Received: April 30, 2020

Accepted: June 7, 2020

Published: June 10, 2020

Copyright $\odot 2020$ by author(s) and Scientific Research Publishing Inc. This work is licensed under the Creative Commons Attribution International License (CC BY 4.0).

http://creativecommons.org/licenses/by/4.0/

\section{(c) (i) Open Access}

\begin{abstract}
Aim: To compare the type of stress distribution pattern occurring with anatomic and non-anatomic tooth forms beneath a complete denture in both maxillary and mandibular arch. Methodology: A photoelastic model of the edentulous maxillary and mandibular ridge was prepared meticulously to simulate the human mandible and maxilla. Two sets of acrylic teeth with anatomic and non-anatomic occlusal forms were used to fabricate upper and lower dentures. A vertical static load of $100 \mathrm{~N}$ was applied through the mandibular model to the maxillary model. After load application on the dentures the photoelastic model as well as the upper and lower complete dentures were sectioned in the midline. The sectioned photoelastic model was viewed through a polariscope to observe the fringe pattern indicating varying amounts of stress distribution. In this study, a two-dimensional photoelastic stress analysis technique was utilized. Results: Force per unit area was observed more in anatomic teeth than the non-anatomic counterpart. Hence anatomic tooth forms may increase the possibility of bone resorption rate over a period of time. However, in non-anatomic lower teeth, a decrease in value was observed from posterior to anterior region. Conclusion: Stress of greater magnitude was observed with cuspal teeth whereas non-anatomic $\left(0^{\circ}\right)$ showed slightly less magnitude of stress. Depending upon the clinical situation the clinician needs to choose the type of occlusal tooth forms for edentulous patients.
\end{abstract}




\section{Keywords}

Complete Denture, Anatomic Tooth Forms, Non Anatomic Tooth Forms, Stress Distribution, Photoelastic Study

\section{Introduction}

Once the patient loses his own teeth due to caries, periodontal problems or trauma; the replacement of the lost tooth can be by fixed or removable prosthesis depending on the extent of tooth loss. Long edentulous spans can only be replaced by implants or removable prosthesis. In cases where economical or systemic factors are the cause of hindrance in the placement of implants, removable prosthesis becomes the sole option. In case of a completely edentulous patient who is not able to afford the implant-retained prosthesis the removable complete denture for maxillary and mandibular is the only choice to restore esthetics and function. In order to withstand the stresses of mastication multiple factors including size, shape and tolerance of residual ridge matter. Retention, support and stability account for changes in the residual ridge [1]. Many authors have studied the measurement of force exerted during mastication with both dentulous and edentulous subjects [2]. There are three definite types of posterior tooth forms namely anatomic, semi-anatomic and non-anatomic $\left(0^{\circ}\right)$. The anatomic porcelain tooth was introduced by Alfred Gysi. The plastic non-anatomic tooth forms came into being in the year 1936 followed by the cross-linked acrylic teeth in 1951 [3]. The key research studies included the efficiency of various tooth forms in relation to their masticatory efficiency and effect of forces on residual ridge [4] [5] [6]. The various stress distribution pattern studies used methods such as electrical strain gauges, photoelastic model [7] and finite element analysis studies. Finite element analysis was the main type of study used to detect forces under the complete denture [8].

Photoelastic study by polariscope: The study carried out by Barber [9] is well known for stress distribution theory. The common stress analysis needs a transparent model made in epoxy resin or araldite. This model is first ensured stress free as discussed in methodology and then the property of birefringence two-fold refraction is observed in the photoelastic model. A polariscope has two polarizers, light source, polarization plate, quarter wave plate, model specimen and load frame. The photoelastic model that's made is placed on load frame and stressed mechanically by placing weight in load hangers. The light sourced is passed on through the models as shown in Figures 1-4 through polarizer. The fringe pattern formed is counted and observed or photographed by looking through the quarter wave plate. When placed between crossed polarizers the polarized light generates a fringe pattern.

The objective of this study was to evaluate the pattern of stress distribution underneath the complete denture with anatomic and non-anatomic tooth forms 
in both edentulous maxillary and mandibular arch using photoelastic models and inspecting the models to observe the type of stress pattern under a polariscope.

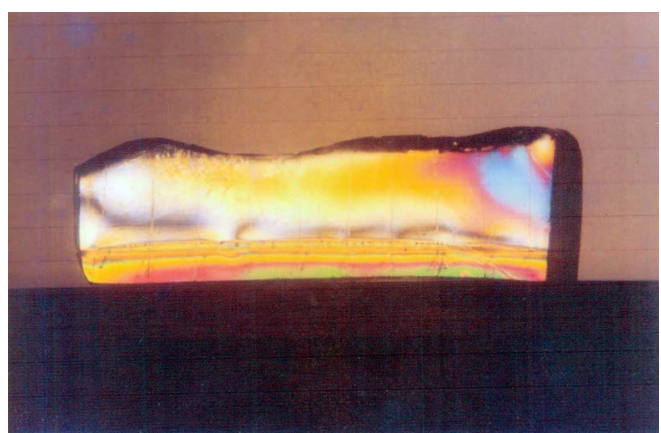

Figure 1. Fringe pattern of non-anatomic right upper teeth.

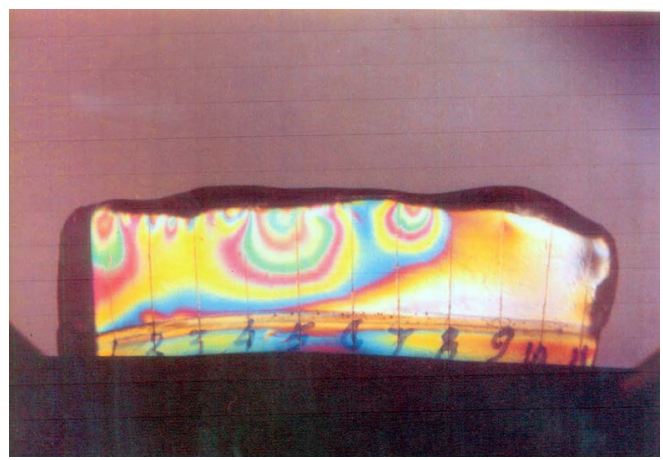

Figure 2. Fringe pattern of anatomic right upper teeth.

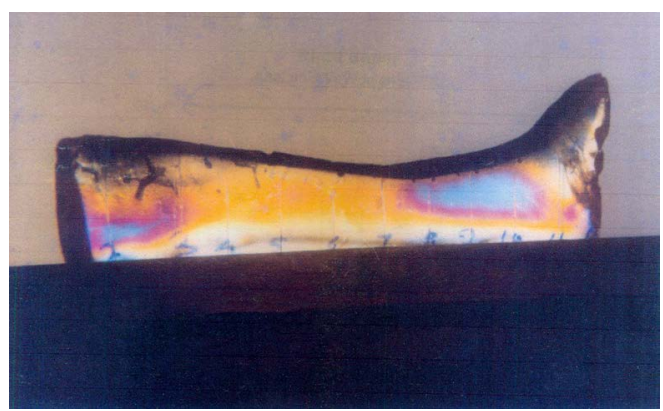

Figure 3. Fringe pattern of non-anatomic right lower teeth.

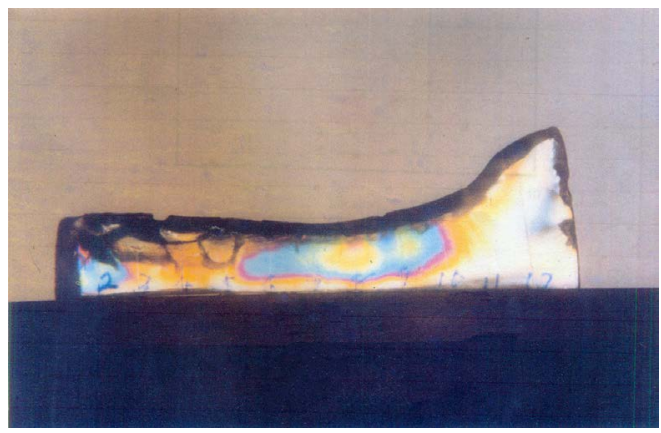

Figure 4. Fringe pattern of anatomic right lower teeth. 


\section{Materials and Methods}

This study was carried out in Government dental college Trivandrum, Kerala, India. The material selected for this study to make photoelastic model was Araldite- a chemically activated epoxy resin. It consists of a base CY 230 and a hardener, HY-951. This material fulfilled the basic requirements of strength, machinability and transparency.

\section{Preparation of Photoelastic Model}

In this study, a model of a medium ridge height and form of edentulous mandibular and maxillary arches are prepared by pouring a photoelastic material (Araldite) into an upper and lower edentulous rubber mould. The resin is mixed in the ratio of $1: 10$

(1 part of hardener and 10 part of the resin) the resin hardener mixture is slowly dispensed accurately into a broad bowl and mixed in one direction to prevent air entrapment with a glass rod. The mixture is mixed slowly for thirty minutes to get a clear mix, and left to set at room temperature in a dry, dust free condition for one day.

The photoelastic model is removed from the mould carefully after it is completely cured and inspected in a polariscope to ensure that it is stress free. Then the models are finished and polished in the routine-manner.

The same mould is used to make stone casts (Type III) of the upper and lower edentulous arches and is recovered when set. On the retrieved cast a $2 \mathrm{~mm}$ thick tin foil was adapted on upper and lower casts to make even space for the elastomeric impression material i.e. polyvinylsiloxane so as to simulate the resiliency of oral mucosa. Over this the upper and lower, heat cured acrylic permanent bases were made. Occlusal rims of standard dimensions are made on the permanent maxillary and mandibular bases and articulated on a semi adjustable articulator. Two sets of teeth both anatomic and non-anatomic were set on the articulated occlusal rims. Maxillary anterior teeth were set first, followed by the mandibular anterior teeth, with the same amount of overjet and overbite for both the dentures. There was no contact between the anterior teeth in the centric occlusion. The posterior part of the lower occlusal plane was established at the junction of anterior two-third and posterior one-third of the retromolar pad. The upper posterior teeth were set after the lower teeth arrangement was completed. These sets were acrylized to form upper and lower complete dentures, Adjustments were made to eliminate processing errors and to restore the original vertical relation of occlusion. After complete curing of the same, the tinfoil was peeled off and substituted with polyvinyl siloxane liner.

\section{Loading Procedure}

The denture in the centric occlusion was stabilized to the photoelastic model. The mounted dentures were kept in position. The assembled denture was kept in a photoelastic oven and a dead weight of $5 \mathrm{Kg}$ was applied on the denture [10]. Care was taken to transfer the load completely to the lower denture. The assembled denture was (stress frozen with load) in which the model was loaded slowly 
at a rate of approximately $5^{\circ} \mathrm{C}-10^{\circ} \mathrm{C} /$ hour, from room temperature to $75^{\circ} \mathrm{C}$, for 1 hour. The stress frozen models were slowly cooled to room temperature at a rate of $3^{\circ} \mathrm{C}$ to $5^{\circ} \mathrm{C}$ /hour and then were taken out from the oven and were analyzed. As stress patterns are appreciated, more on a flat body due to the properties of light rays, the curved photoelastic model was split into two and one of the halves was used for the study. The upper and lower complete dentures were split into two, in the midline by using a hacksaw blade. Since both halves were identical only one half was taken for the study. Slices were prepared from the cut portion of the photoelastic model. The fringe order in the slices was measured using a transmission polariscope.

Transmission polariscope: is an instrument used to generate and convert light into circular polarized light which is used to analyze stressed photoelastic models. Light sources were of two types white light and sodium vapor lamp (monochromatic light). Polarizing and analyzing components were identical except for the arrangement of plates. Each consisted of a polarizing filter and a quarter wave plates. The model to be studied was placed in between the polarizing and analyzing unit and viewed through the analyzer. The fringe orders were measured using a Babinel solid compensator. The analysis of the stressed model was done as suggested by Dally and Max [11].

$$
F=\frac{8 P}{T T D N} \text { Dally \& Riley }
$$

where $F=$ Fringe value of material;

$P=$ Load applied in the disk $-2 \mathrm{Kg}$;

$D=$ Diameter of disk;

$N=$ Fringe order at the center of disk $\mathrm{Kg} / \mathrm{cm} /$ fringe.

$$
\left(\sigma_{1}-\sigma_{2}\right)_{2} \frac{N F}{f}\left(\sigma_{p}-\sigma_{m}\right)_{2}=\frac{\text { Actual load }}{\text { Load applied on the proto model }}
$$

The stresses were then calculated using the formula as described above equation.

The stresses were then calculated using the formula as described in the above equation. The values of stress fringe coefficient, $f$, was determined using a disc under diameter compression kept along with the model and subjected to the same stress freezing cycle. The stresses at various locations in different slices are presented in Tables 1-4. The comparison of stresses in the anatomic and non-anatomic teeth is presented graphically through Figure 6 and Figure 7. The picture of the photoelastic model and the photoelastic fringe pattern (stress pattern) for various slices are shown in Figures 1-4.

\section{Results}

\section{Analysis of Anatomic and Non-Anatomic Teeth}

\section{Calibration}

Compensator constant $=50$;

Disk diameter $=50$; 
Thickness $(\mathrm{mm})=3.33$;

Load = $2 \mathrm{Kg}$;

Fringe order at center of disk $=4.04$;

Fringe stress coefficient $=0.2522$;

Araldite at $65 \mathrm{c} \mathrm{Kg} / \mathrm{cm} /$ Fringe.

Model Analysis

Load applied on the model $5 \mathrm{Kg}$;

Proto load $50.96 \mathrm{Kg}(500 \mathrm{~N})$.

Table 1. Stress values of non-anatomic right upper teeth.

\begin{tabular}{cccc}
\hline \multicolumn{4}{c}{ Non Anatomic Right Upper } \\
\hline Location & Fringe order & Model stress ksc & Proto stress ksc \\
\hline CI & 1.74 & 0.70 & 7.10 \\
LI & 0.40 & 0.16 & 1.61 \\
C & 0.36 & 0.15 & 1.52 \\
I PM & 0.48 & 0.20 & 1.99 \\
II PM & 0.50 & 0.20 & 2.04 \\
IM & 0.52 & 0.20 & 2.09 \\
II M & 1.08 & 0.44 & 4.48 \\
III M & 1.42 & 0.59 & 5.98 \\
DB & 1.44 & 0.60 & 6.07 \\
\hline
\end{tabular}

Table 2. Stress values of anatomic right upper teeth.

\begin{tabular}{cccc}
\hline \multicolumn{2}{c}{ Anatomic Right Upper } & \\
\hline Location & $\begin{array}{c}\text { Fringe } \\
\text { order }\end{array}$ & Model stress ksc & $\begin{array}{c}\text { Proto } \\
\text { stress } \\
\text { ksc }\end{array}$ \\
\hline CI & 1.68 & 0.74 & 7.58 \\
LI & 1.54 & 0.67 & 6.83 \\
C & 0.82 & 0.36 & 3.63 \\
I PM & 2.40 & 1.03 & 10.46 \\
II PM & 1.16 & 0.50 & 5.14 \\
IM & 1.28 & 0.54 & 5.48 \\
II M & 2.02 & 0.85 & 8.66 \\
III M & 0.48 & 0.21 & 2.09 \\
DB & 0.48 & 0.22 & 2.20 \\
\hline
\end{tabular}


Table 3. Stress values of non-anatomic right lower teeth.

\begin{tabular}{clcc}
\hline Location & $\begin{array}{c}\text { Non-Anatomic Right Lower } \\
\text { order }\end{array}$ & Model stress ksc & $\begin{array}{c}\text { Proto } \\
\text { stress } \\
\text { ksc }\end{array}$ \\
\hline CI & 0.04 & 0.02 & 0.21 \\
LI & 0.04 & 0.02 & 0.21 \\
C & 0.04 & 0.02 & 0.23 \\
I PM & 0.60 & 0.28 & 2.80 \\
II PM & 0.44 & 0.20 & 2.02 \\
IM & 0.60 & 0.27 & 2.71 \\
II M & 1.74 & 0.76 & 7.71 \\
III M & 1.36 & 0.60 & 6.13 \\
DB & 2.94 & 1.32 & 13.50 \\
\hline
\end{tabular}

Table 4. Stress values of anatomic right lower teeth.

\begin{tabular}{cccc}
\hline \multicolumn{4}{c}{ Anatomic Right Lower } \\
\hline Location & $\begin{array}{c}\text { Fringe } \\
\text { order }\end{array}$ & Model stress ksc & $\begin{array}{c}\text { Proto } \\
\text { stress } \\
\text { ksc }\end{array}$ \\
\hline CI & 0.84 & 0.47 & 4.80 \\
LI & 0.80 & 0.40 & 4.11 \\
C & 1.40 & 0.64 & 6.54 \\
I PM & 1.06 & 0.50 & 5.05 \\
II PM & 1.02 & 0.49 & 4.95 \\
IM & 2.16 & 0.96 & 9.74 \\
II M & 2.84 & 1.21 & 12.38 \\
III M & 4.94 & 2.08 & 21.17 \\
DB & 3.34 & 1.40 & 14.31 \\
\hline
\end{tabular}

\section{Results for Proto stress values on maxillary model:}

Table 1 indicates stress values for non-anatomic teeth in the upper right half, the highest stress value of $7.10 \mathrm{ksc}$ was found in the incisor region and the lowest stress value of $1.52 \mathrm{ksc}$ was seen in the canine region of non-anatomic teeth. In non-anatomic teeth the greater stress was observed towards the anterior region.

In Table 2 (Anatomic upper right half) a still higher value of $10.46 \mathrm{ksc}$ was observed in the premolar region and $2.09 \mathrm{ksc}$ as the lowest value in the $2^{\text {nd }}$ molar region. In the anatomic teeth, however, a definite variation in stress values was not observed. Even though such a definite variation was not observed the stress values were markedly greater throughout the model than in the non-anatomic teeth. 


\section{Results for Proto stress values on mandibular model:}

In Table $3 \&$ Table 4 (Non-anatomic lower right half) a high stress value 13.50 ksc observed behind the set teeth and 2nd molar tooth showed the highest value of $7.71 \mathrm{ksc}$.

In anatomic lower, a value of $21.17 \mathrm{ksc}$ was observed in the lower ridge area and the $2^{\text {nd }}$ molar region a stress value of $13.46 \mathrm{ksc}$ was observed.

Compared to non-anatomic teeth, anatomic teeth showed high stress concentration. The highest stress value for anatomic tooth is $4.11 \mathrm{ksc}$ and for non-anatomic is $0.21 \mathrm{ksc}$ and the difference between anatomic and non-anatomic stress value is $3.9 \mathrm{ksc}$.

Statistical analysis: The data are expressed in mean and standard deviation. Statistical Package for Social Sciences (SPSS 16.0) version was used for analysis. ANOVA (Post hoc) followed by an unpaired $t$ test applied to find the statistical significance between the groups. $\mathrm{p}$ value less than 0.05 considered statically significant at $95 \%$ confidence interval.

The results obtained from the experiment were recorded photographically as well as numerically, when photoelastic models are utilized for studying stress distribution patterns, the experimenter is able to visibly analyze the direction and magnitude of stress developing within the models. In addition to the visual display, the compensator device helps to accurately compute the numerical value of fringe order at desirable points along the entire length of the model and stresses are calculated from the fringe order. On evaluation, the following stress values were found for anatomic teeth and non-anatomic teeth as shown in Tables 1-4 and comparative evaluation between anatomic and non-anatomic in Table 5 and Table 6. The graphs and photoelastic images are in Figures 1-9.

Table 5. Comparison of fringe order, model stress ksc and proto stress ksc values between non-anatomic and anatomic right upper side.

\begin{tabular}{ccccccc}
\hline \multirow{2}{*}{ Location } & \multicolumn{2}{c}{ Fringe order } & \multicolumn{2}{c}{ Model stress ksc } & \multicolumn{2}{c}{ Proto stress ksc } \\
\cline { 2 - 7 } & NARS & ARS & NARS & ARS & NARS & ARS \\
\hline CI & $1.74 \pm 0.12$ & $1.68 \pm 0.12$ & $0.70 \pm 0.24$ & $0.74 \pm 0.34$ & $7.10 \pm 1.78$ & $7.58 \pm 0.47$ \\
LI & $0.40 \pm 0.23$ & $1.54 \pm 1.34^{*}$ & $0.16 \pm 0.16$ & $0.67 \pm 0.45$ & $1.61 \pm 0.45$ & $6.83 \pm 0.67^{*}$ \\
C & $0.36 \pm 0.13$ & $0.82 \pm 0.67$ & $0.15 \pm 0.45$ & $0.36 \pm 0.14$ & $1.52 \pm 0.89$ & $3.63 \pm 0.15^{*}$ \\
I PM & $0.48 \pm 0.45$ & $2.40 \pm 0.45^{*}$ & $0.20 \pm 0.89$ & $1.03 \pm 0.56^{*}$ & $1.99 \pm 0.13$ & $10.46 \pm 0.86^{*}$ \\
II PM & $0.50 \pm 0.56$ & $1.16 \pm 0.67^{*}$ & $0.20 \pm 0.17$ & $0.50 \pm 0.18$ & $2.04 \pm 0.93$ & $5.14 \pm 0.56^{*}$ \\
IM & $0.52 \pm 0.83$ & $1.28 \pm 0.13^{*}$ & $0.20 \pm 0.89$ & $0.54 \pm 0.34$ & $2.09 \pm 0.45$ & $5.48 \pm 0.43^{*}$ \\
II M & $1.08 \pm 0.80$ & $2.02 \pm 0.14^{*}$ & $0.44 \pm 0.12$ & $0.85 \pm 0.89$ & $4.48 \pm 0.23$ & $8.66 \pm 0.14^{*}$ \\
III M & $1.42 \pm 0.45$ & $0.48 \pm 0.13^{*}$ & $0.59 \pm 0.34$ & $0.21 \pm 0.13$ & $5.98 \pm 0.45$ & $2.09 \pm 0.16^{*}$ \\
DB & $1.44 \pm 0.89$ & $0.48 \pm 0.12^{*}$ & $0.60 \pm 0.45$ & $0.22 \pm 0.34$ & $6.07 \pm 0.16$ & $2.20 \pm 0.12^{*}$ \\
\hline
\end{tabular}

${ }^{*} \mathrm{p}<0.05$ significant compared upper non-anatomic right side with anatomic upper side. 
Table 6. Comparison of fringe order, model stress ksc and proto stress ksc values between non-anatomic and anatomic right lower side.

\begin{tabular}{|c|c|c|c|c|c|c|}
\hline \multirow{2}{*}{ Location } & \multicolumn{2}{|c|}{ Fringe order } & \multicolumn{2}{|c|}{ Model stress ksc } & \multicolumn{2}{|c|}{ Proto stress ksc } \\
\hline & NARS & ARS & NARS & ARS & NARS & ARS \\
\hline CI & $0.04 \pm 0.34$ & $0.84 \pm 0.43^{*}$ & $0.02 \pm 0.56$ & $0.47 \pm 0.45^{\star}$ & $0.21 \pm 0.14$ & $4.80 \pm 0.13^{*}$ \\
\hline LI & $0.04 \pm 0.17$ & $0.80 \pm 0.56^{*}$ & $0.02 \pm 0.18$ & $0.40 \pm 0.34^{\star}$ & $0.21 \pm 0.15$ & $4.11 \pm 0.10^{\star}$ \\
\hline $\mathrm{C}$ & $0.04 \pm 0.45$ & $1.40 \pm 0.10$ & $0.02 \pm 0.15$ & $0.64 \pm 0.23^{\star}$ & $0.23 \pm 0.34$ & $6.54 \pm 0.45^{\star}$ \\
\hline I PM & $0.60 \pm 0.55$ & $1.06 \pm 0.13$ & $0.28 \pm 0.83$ & $0.50 \pm 0.67$ & $2.80 \pm 0.13$ & $5.05 \pm 0.83^{*}$ \\
\hline II PM & $0.44 \pm 0.18$ & $1.02 \pm 0.67$ & $0.20 \pm 0.13$ & $0.49 \pm 0.43$ & $2.02 \pm 0.10$ & $4.95 \pm 0.56^{*}$ \\
\hline IM & $0.60 \pm 0.32$ & $2.16 \pm 0.94^{\star}$ & $0.27 \pm 0.54$ & $0.96 \pm 0.19^{\star}$ & $2.71 \pm 0.18$ & $9.74 \pm 0.18^{\star}$ \\
\hline II M & $1.74 \pm 0.18$ & $2.84 \pm 0.47^{*}$ & $0.76 \pm 0.32$ & $1.21 \pm 0.19$ & $7.71 \pm 0.17$ & $12.38 \pm 0.15^{\star}$ \\
\hline III M & $1.36 \pm 0.45$ & $4.94 \pm 0.18^{*}$ & $0.60 \pm 0.45$ & $2.08 \pm 0.82^{\star}$ & $6.13 \pm 0.18$ & $21.17 \pm 0.13^{*}$ \\
\hline DB & $2.94 \pm 0.56$ & $3.34 \pm 0.45^{*}$ & $1.32 \pm 0.56$ & $1.40 \pm 0.18$ & $13.50 \pm 0.89$ & $14.31 \pm 0.67^{\star}$ \\
\hline
\end{tabular}

${ }^{*} \mathrm{p}<0.05$ significant compared lower non-anatomic right side with anatomic upper side.

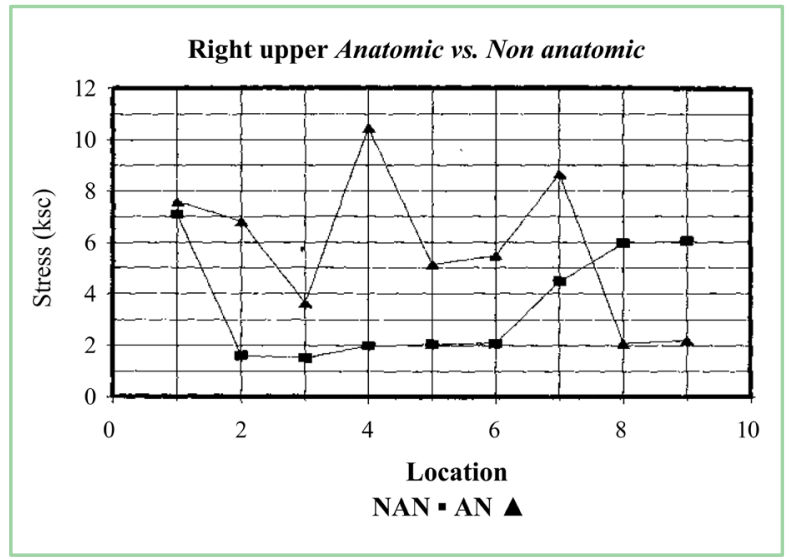

Figure 5. Comparison of stresses in anatomic and nonanatomic teeth (right upper).

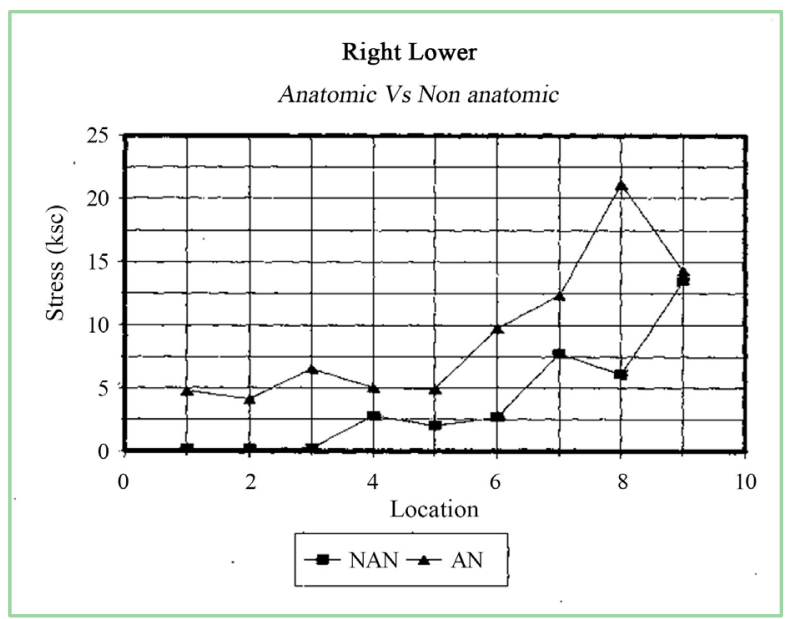

Figure 6. Comparison of stresses in anatomic and non-anatomic teeth (right lower). 


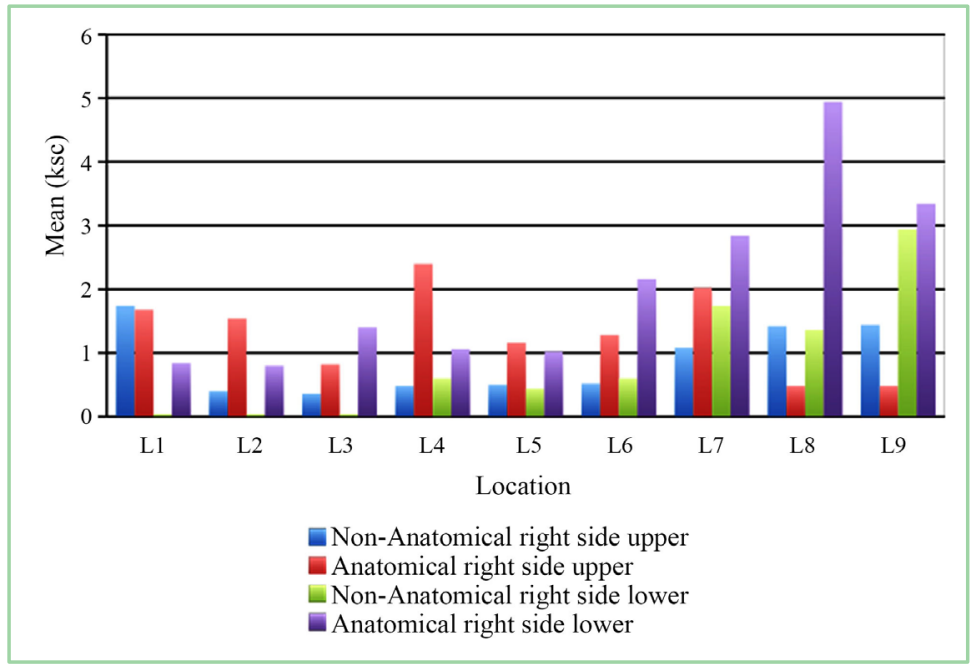

Figure 7. Comparison of fringe order values between non-anatomic and anatomic right upper and lower sides.

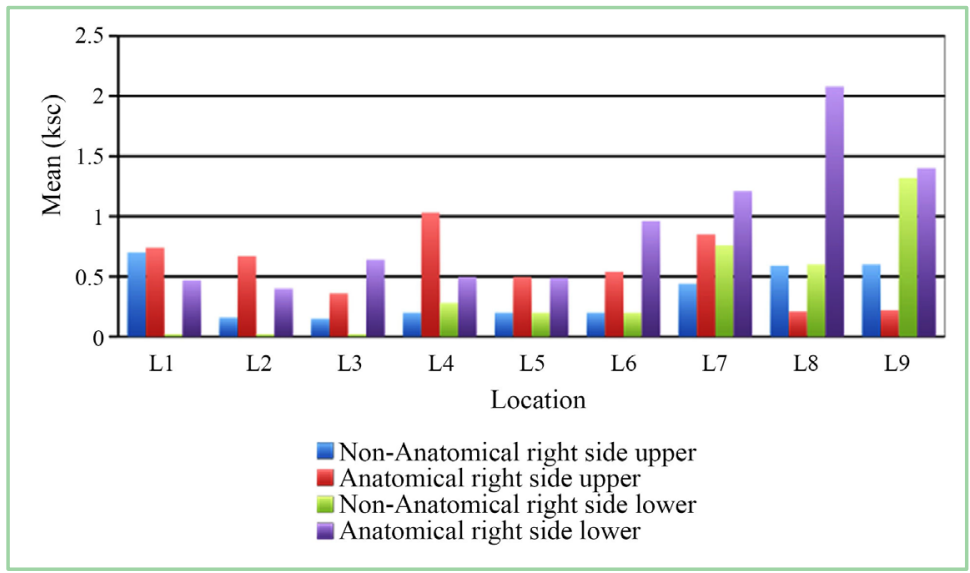

Figure 8. Comparison of model stress ksc values between non-anatomic and anatomic right upper and lower sides.

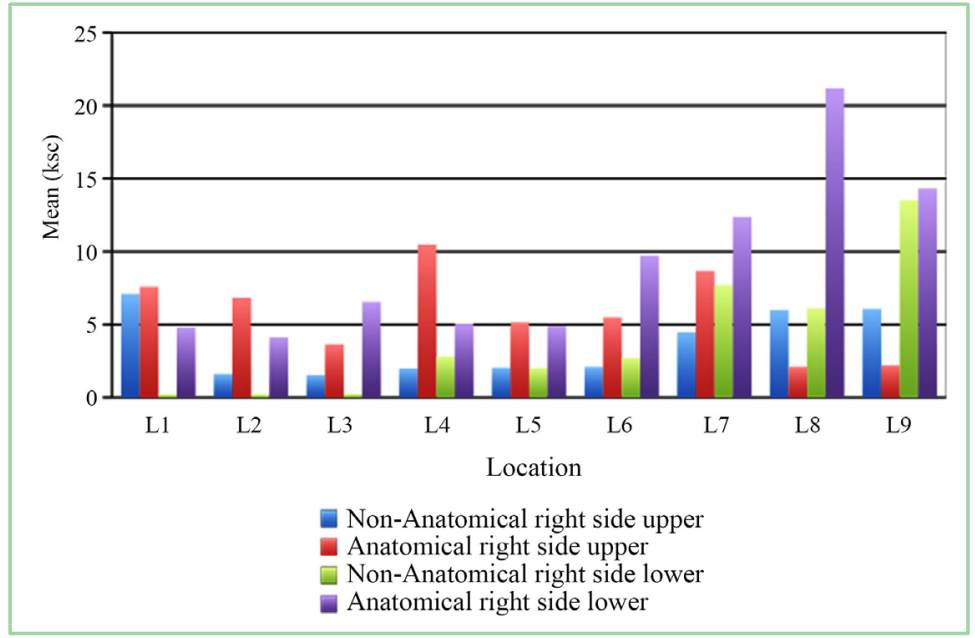

Figure 9. Comparison of proto stress ksc values between non-anatomic and anatomic right upper and right lower sides. 


\section{Discussion}

In the anatomic teeth, peak stresses were almost two times more than in the non-anatomic teeth (Table 2 and Table 4). This is the expected result because upper and lower anatomic teeth when occluded in maximum intercuspation do not come into contact with the total occlusal surface areas due to the cuspal morphology. The masticatory forces therefore are concentrated on specific areas on the occlusal surfaces of the upper and lower occluding teeth. As a result the force per unit area, in anatomic teeth was considered more than non-anatomic teeth [12]. But in monoplane teeth complete occlusal surface contact is there with upper and lower teeth in occlusion. Therefore the stresses generated due to the normal masticatory load were bound to be scattered over a large area and as a result force per unit area was considerably less than in anatomic teeth [13]. In non-anatomic tooth as enhanced force per unit area was observed a rapid rate of bone resorption is reported and confirmed from earlier studies [14]. It was also observed that the depth of stressed areas or the quality of penetration was higher in anatomic teeth rather than non-anatomic teeth, since the masticatory loads concentrated on a much lesser area in anatomic teeth. Since anatomic teeth had definite angulation in all their cusps, the masticatory forces which came into contact with these inclined surfaces instead of passing vertically downwards gave rise to two resultant forces, one in the posterior direction and the other in the anterior direction [15].

Contrary to the result obtained in anatomic teeth, the stresses in the non-anatomic teeth were distributed over a wider area and had a tendency to diffuse (Table 1 and Table 3 ). This was because the contacts of the occlusal surfaces of the antagonist teeth were much more even and uniform, thereby not allowing the stresses to concentrate in any definite area. Due to the nature of this flat contact the stresses were transmitted only in a vertical direction under every point below the occlusal surface areas. When loads were increased the area tends to diffuse further. No resultant forces were generated in non-anatomic tooth contact. This fact has also been confirmed by Sharry [16]. In case of lower anatomic teeth the stressed areas concentrated more below the molars than premolars. The logical explanation could be the fact that the molars have a larger occlusal surface area than premolars [17]. The transmission of forces and also the number of fringes increased with the increase in occlusal surface area. Therefore, the stress concentration under premolars was less.

\section{Interpretation of photoelastic fringes and stress pattern:}

The number of isochromatic fringes observed is directly proportional to the stress in the photoelastic resin model. Fringe crowding is due to high stress concentration (Table 7).

The tint of passage is a sharp dividing zone between red and blue in the first-order fringe, red and green in the second-order fringe and pink and green in the third order fringes. With white light only the first five fringes can be observed. In this study the photoelastic stress image in Figures 2-6 shows the fringe pattern on 
Table 7. The sequence of coloured fringe order.

\begin{tabular}{|c|c|}
\hline Black & 0.00 \\
\hline Grey & 0.28 \\
\hline White & 0.45 \\
\hline Yellow & 0.60 \\
\hline Orange & 0.79 \\
\hline Red & 0.90 \\
\hline Tint of passage 1 & 1.00 \\
\hline Blue & 1.06 \\
\hline Blue green & 1.20 \\
\hline Green yellow & 1.38 \\
\hline Orange & 1.62 \\
\hline Red & 1.81 \\
\hline Tint of passage 2 & 2.00 \\
\hline Green & 2.33 \\
\hline Green-yellow & 2.50 \\
\hline Pink & 2.67 \\
\hline Tint of passage 3 & 3.00 \\
\hline Green & 3.10 \\
\hline Pink & 3.60 \\
\hline Tint of passage 4 & 4.00 \\
\hline Green & 4.13 \\
\hline
\end{tabular}

edentulous models of maxillary and mandibular with anatomic and non-anatomic tooth forms. From the present study it was obvious that when anatomic teeth were used, the depth of penetration, the force per unit area and the intensity of stress were significantly higher than non-anatomic teeth when stressed [18] (Figures 1-4). Therefore, the chances of bone resorption were much higher when anatomic teeth were used. The photoelastic models showed visible and striking changes in relation to the fringe pattern (area, width, depth and intensity). At each stage photographs were made using color films and zoom lenses.

\section{Conclusions}

1) Non-anatomic teeth produced a uniform and diffused area of stress. In anatomic teeth stresses tended to concentrate only in specific areas of the photoelastic model. The intensity of the stress was more in case of anatomic teeth than in non-anatomic teeth, which may increase the possibility in the rate of bone resorption.

2) Fringes, which occured due to stresses, concentrated more below the molars than premolars in case of lower teeth.

3) Force applied on the anatomic teeth was split into two different compo- 
nents. This was due to the cuspal inclination of the anatomic teeth. No such differentiation was seen when non-anatomic teeth were used and the forces were transmitted in a purely vertical direction.

4) Depending upon the condition of the residual alveolar ridge the operator can select the type of occlusal form of the posterior teeth to be used.

\section{Conflicts of Interest}

The authors declare no conflicts of interest regarding the publication of this paper.

\section{References}

[1] Atwood, D.A. (1971) Reduction of Residual Ridges: A Major Oral Disease Entity. Journal of Prosthetic Dentistry, 26, 266-279. https://doi.org/10.1016/0022-3913(71)90069-2

[2] Lawson, W.A. (1960) The Validity of a Method Used for Measuring Masticatory Forces. Journal of Prosthetic Dentistry, 10, 99-111. https://doi.org/10.1016/0022-3913(60)90095-0

[3] Winkler, S. (1979) Essentials of Complete Denture Prosthodontics. W.B. Saunders Company, Philadelphia, 322.

[4] Inove, S., Kawano, F., Nagao, K. and Matsumoto, N. (1996) An in Vitro Study of the Influence of Occlusal Scheme on the Pressure Distribution of Complete Denture Supporting Tissues. International Journal of Prosthodontics, 9, 179-187.

[5] Frechette, A.R. (1955) Comparison of Balanced and Non-Balanced Occlusion of Artificial Dentures Based upon Distribution of Masticatory Force. Journal of Prosthet ic Dentistry, 5, 801-809. https://doi.org/10.1016/0022-3913(55)90156-6

[6] Takayama, Y., Yamada, T., Araki, O., Seki, T. and Kawasaki, T. (2001) The Dynamic Behavior of a Lower Complete Denture during Unilateral Loads: Analysis Using the Finite Element Method. Journal of Oral Rehabilitation, 28, 1064-1074. https://doi.org/10.1046/j.1365-2842.2001.00759.x

[7] Lopuck, S., Smith, J. and Caputo, A. (1978) Photoelastic Comparison of Posterior Denture Occlusion. Journal of Prosthetic Dentistry, 40, 18-21. https://doi.org/10.1016/0022-3913(78)90152-X

[8] Nishigawa, G., Matsunaga, T., Maruo, Y., Okamoto, M., Natsuaki, N. and Minagi, S. (2003) Finite Element Analysis of the Effect of the Denture Supporting Bone of the Edentulous Patient. Journal Oral Rehabilitation, 30, 646-652. https://doi.org/10.1046/j.1365-2842.2003.01110.x

[9] Barber, J.R. (2010) Elasticity. Springer Netherlands. [Fro41] Max Mark Frocht. Photoelasticity. J. Wiley, New York, 1941.

[10] Thomson, J.C. (1971) The Load Factor in Complete Denture Intolerance. Journal of Prosthetic Dentistry, 25, 4-11. https://doi.org/10.1016/0022-3913(71)90143-0

[11] Dally, J.W. and Riley, W.F. (1965) Experimental Stress Analysis. McGraw Hill Book Company, New York.

[12] Rangarajan, V., Yogesh, P.B., Gajapathi, B., Ibrahim, M.M., Kumar, R.G. and Karthik, M. (2016) Concepts of Occlusion in Prosthodontics: A Literature Review, Part II. Journal of Indian Prosthodontic Society, 16, 8-14. https://doi.org/10.4103/0972-4052.164915

[13] Hafezeqoran, A., Koodaryan, R., Noorazar, S.G., Hajialilue-Bonab, M., Hassanza- 
deh, M. and Yasamineh, N. (2018) Evaluation of Strain in Mandibular Denture-Supporting Area in Three Different Occlusal Schemes during Jaw Movements. Journal of Dental Research, Dental Clinics, Dental Prospects, 12, 18-25. https://doi.org/10.15171/joddd.2018.004

[14] Woelfel, J.B., Winter, C.M. and Igarshi, T. (1976) Five Year Cephalometric Study of Mandibular Ridge Resorption with Different Posterior Occlusal Forms. Part I Denture Construction and Initial Comparison. Journal of Prosthetic Dentistry, 36, 602-623. https://doi.org/10.1016/0022-3913(76)90025-1

[15] Swoope, C.C. and Kydd, W.L. (1966) The Effect of Cusp Form and Occlusal Surface Area on Denture Base Deformation. Journal Prosthetic Dentistry, 16, 34-43. https://doi.org/10.1016/0022-3913(66)90110-7

[16] Sharry, J.J., Askew, H.C. and Hoyer, H. (2015) Influence of Artificial Tooth Forms on Bone Deformation beneath Complete Dentures. Journal of Restorative Dentistry, 39, 253-266. https://doi.org/10.1177/00220345600390020701

[17] Nakatsuka, Y., Yamashita, S., Nimura, H., Mizoue, S., Tsuchiya, S. and Hashii, K. (2010) Location of Main Occluding Areas and Masticatory Ability in Patients with Reduced Occlusal Support. Australian Dental Journal, 55, 45-50. https://doi.org/10.1111/j.1834-7819.2009.01174.x

[18] Lambrecht, J.R. and Kydd, W.L. (1962) A Functional Stress Analysis of the Maxillary Complete Denture Base. Journal of Prosthetic Dentistry, 12, 865.

https://doi.org/10.1016/0022-3913(62)90039-2 